

\section{Shifting Foundations}

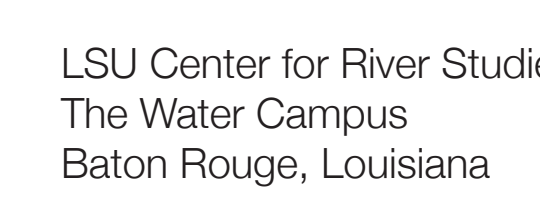



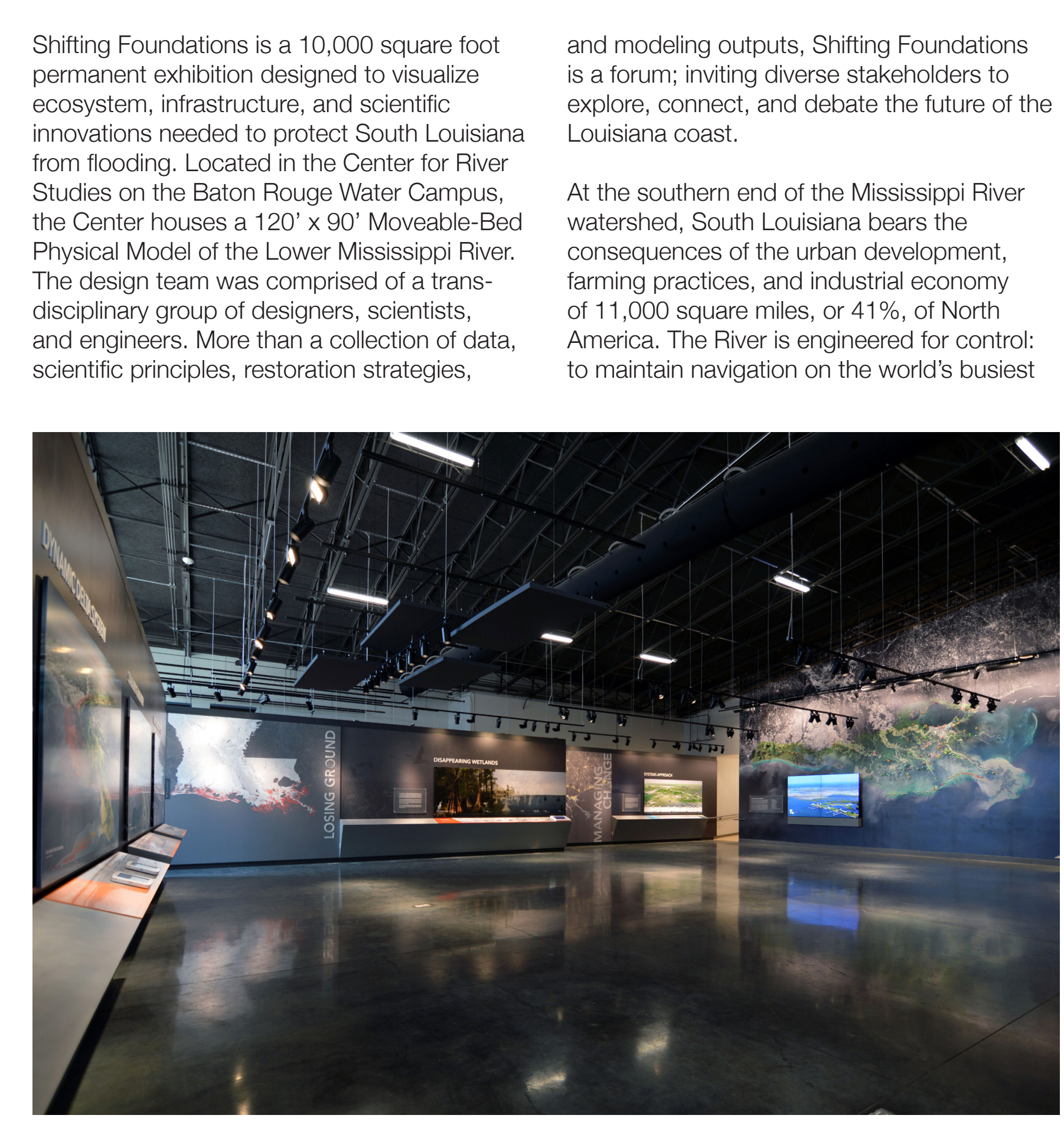



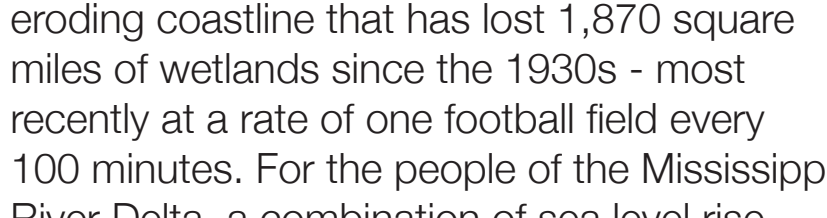

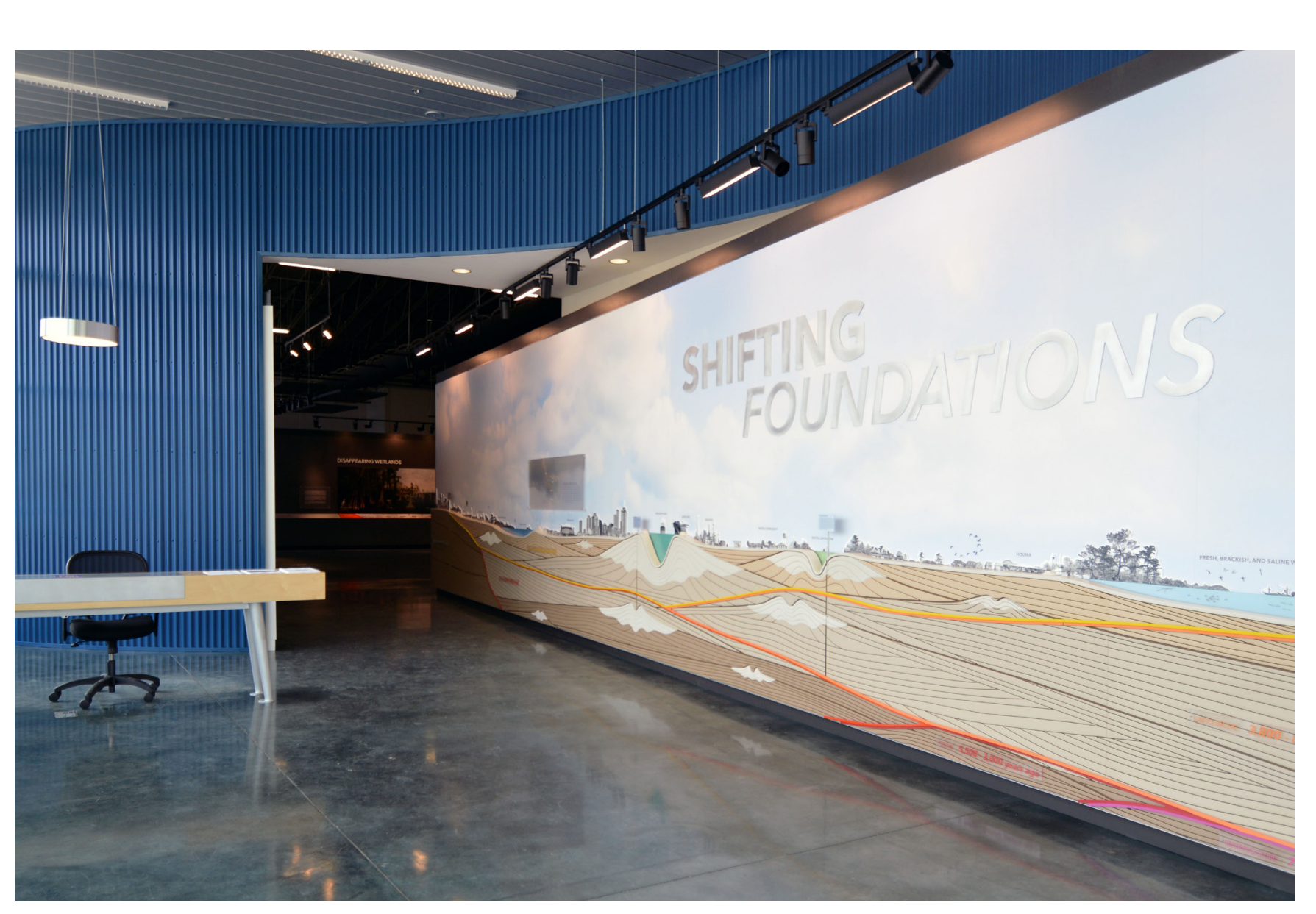



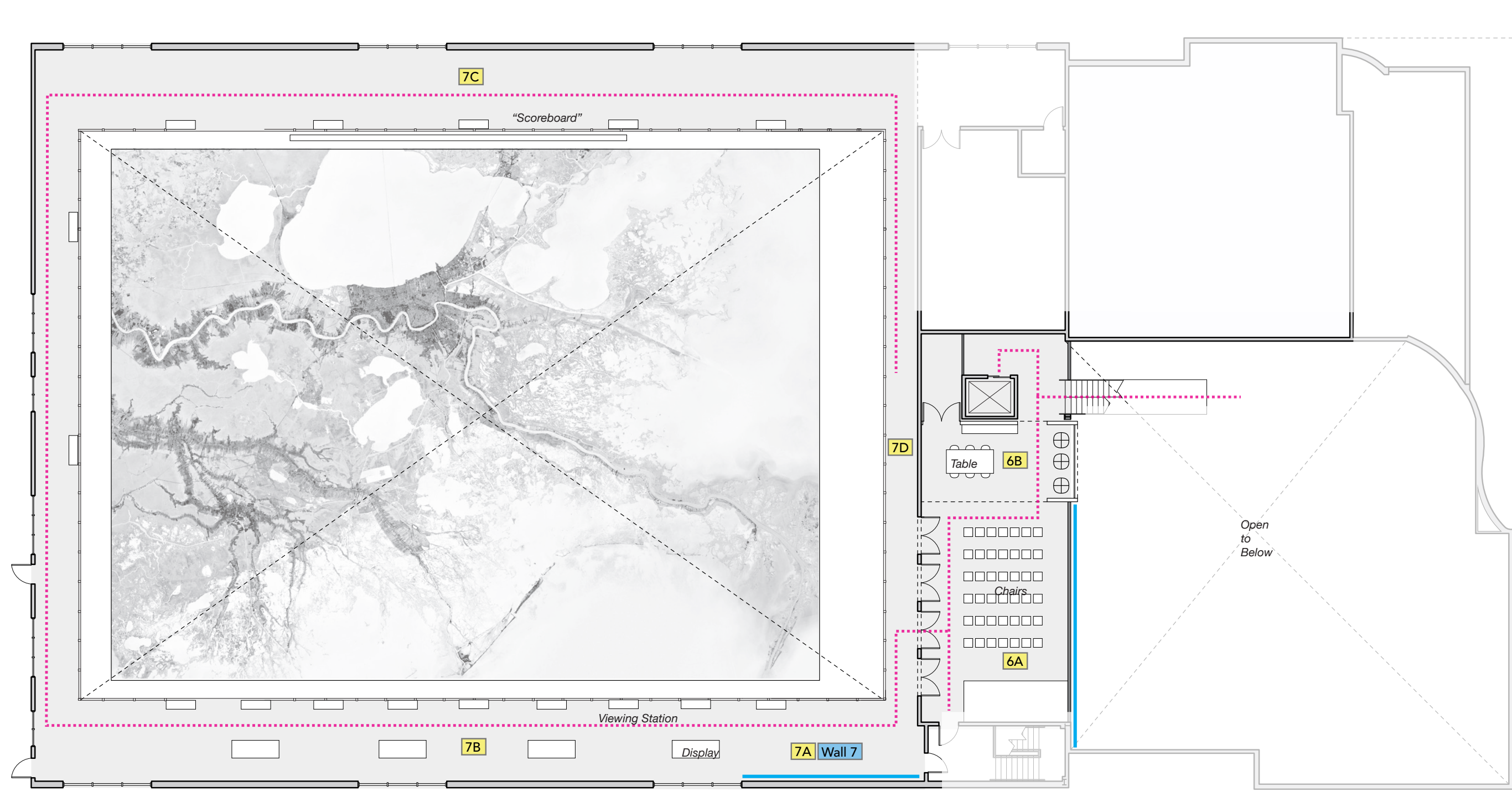

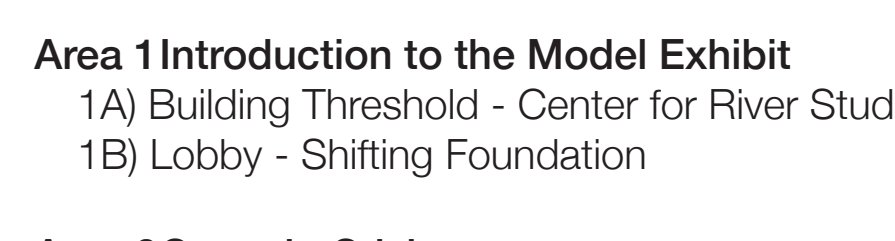



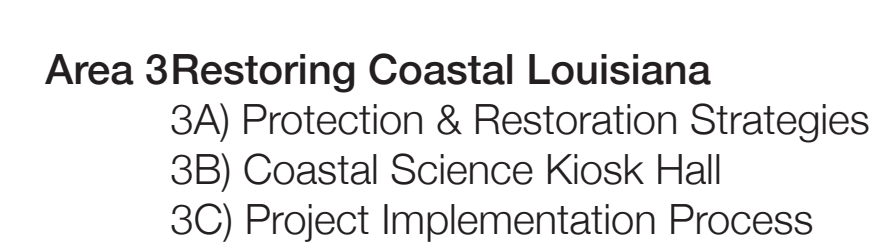

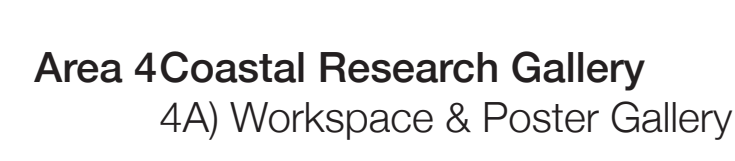

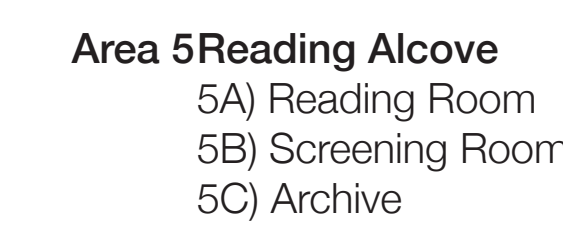

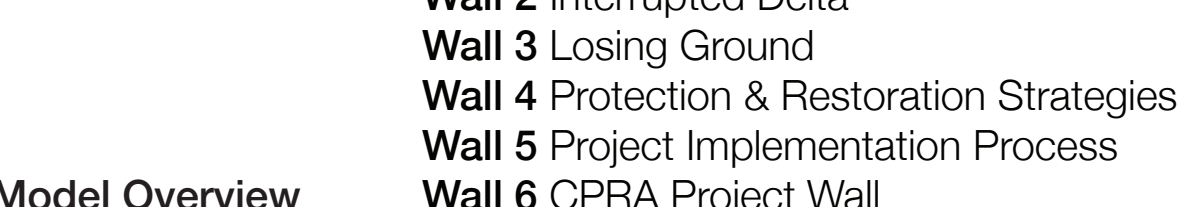

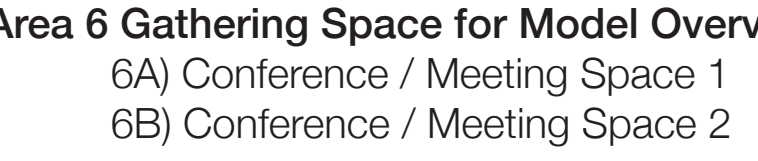

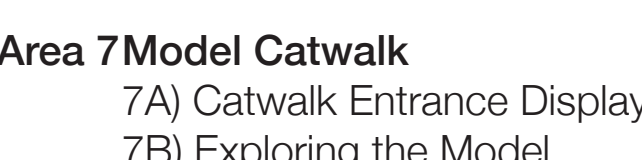





